\title{
EL APROVECHAMIENTO DE LOS ANIMALES EN EL VALLE DE YOCAVIL (CATAMARCA, ARGENTINA): EL CASO DEL SITIO TARDÍO (SIGLOS XI-XVI D.C.) LOMA RICA DE SHIQUIMIL
}

\section{USE OF ANIMALS IN THE YOCAVIL VALLEY (CATAMARCA, ARGENTINA): THE CASE STUDY OF THE LATE SITE (11TH TO 16TH CENTURY AD) LOMA RICA DE SHIQUIMIL}

\author{
María Clara Álvarez¹, Carlos R. Belotti López de Medina², Catriel Greco³ \\ 1UE Investigaciones Arqueológicas y Paleontológicas del Cuaternario Pampeano \\ INCUAPA-CONICET, Facultad de Ciencias Sociales, Universidad Nacional del Centro de la \\ Provincia de Buenos Aires (UNICEN). Av. Del Valle 5737 (CP B7400JWI) Olavarría, Buenos \\ Aires, Argentina. E-mail: malvarez@soc.unicen.edu.ar \\ ${ }_{2}^{2}$ Instituto de las Culturas (IDECU, Universidad de Buenos Aires, CONICET). Museo \\ Etnográfico “J. B. Ambrosetti”. Moreno 350 (CP 1091), Ciudad Autónoma de Buenos Aires. \\ E-mail: crbelotti@filo.uba.ar \\ ${ }^{3}$ CONICET - Departamento de Geología, Universidad Nacional de San Luis. Ejército de Los \\ Andes 950 (CP 5700) San Luis, Argentina. E-mail: catrielgreco@conicet.gov.ar
}

Presentado: 23/02/2021

Aceptado: 24/5/2021

\section{Resumen}

El sitio Loma Rica de Shiquimil se ubica en los Valles Calchaquíes (Noroeste argentino) y corresponde al período conocido como Tardío o Desarrollos Regionales (ca. siglos XI-XVI d.C.). En este trabajo se presentan los resultados del análisis de los materiales faunísticos de recientes excavaciones con los objetivos de evaluar el aprovechamiento de animales, la presencia de camélidos domésticos y silvestres, la estacionalidad de las ocupaciones y los procesos de formación, entre otros. La metodología incluyó la determinación taxonómica y anatómica de los especímenes, así como el uso de medidas de abundancia taxonómica y anatómica y la aplicación de análisis morfométricos. Asimismo, se consideraron diferentes variables que permitieron evaluar la acción de agentes naturales y culturales sobre los restos. En total, se analizaron 1503 especímenes óseos. Los resultados indican un predominio de los camélidos, entre los cuales se determinó al menos un individuo asignable a Vicugna vicugna y otro a Lama sp. Se determinaron animales de diferentes edades $y$ distintas actividades vinculadas con su procesamiento y consumo. Este trabajo aporta nuevos datos que permiten discutir el uso de los animales en el Período Tardío, momento para el cual los datos sobre la subsistencia son aún escasos.

Palabras claves: Valles Calchaquíes, camélidos, Período Tardío, poblados defensivos, pukara. 


\begin{abstract}
The Loma Rica de Shiquimil archaeological site is located at the Calchaqui Valleys (Northwestern Argentina) and was dated to the Late Period, also known as Regional Developments (ca. from the $11^{\text {th }}$ to $16^{\text {th }}$ century $A D$ ). We present the results of the analysis conducted on the faunal remains recovered during the last fieldwork season. Our research objectives are to assess the utilization of animals at the site, the occurrence of wild and domestic camelids species, as well as proxies of seasonality, and site formation processes. Our analyses included taxonomic and anatomical identification of bone specimens, multivariate analysis of morphometric measurements, recording of bone modifications by natural and cultural processes, and, finally, quantification of primary data. In total, 1503 bone specimens were analyzed. Results indicate the predominance of camelids, among which at least one individual of Vicugna vicugna and another of Lama sp. were identified. Camelid specimens corresponding to different age-groups were identified and diverse activities related to their butchering and consumption were established. This research provides new data that contributes to the ongoing discussion regarding animal utilization during the Late Period, for which data on subsistence activities remains scarce.
\end{abstract}

Keywords: Calchaqui Valleys, camelids, Late Period, defensive settlements, pukara.

\title{
Introducción
}

El presente trabajo describe las arqueofaunas del sitio Loma Rica de Shiquimil, un poblado tipo pukara o defensivo del sudeste de los Valles Calchaquíes (Noroeste argentino) datado en el período Tardío o Desarrollos Regionales (ca. siglos XI-XVI d.C.). Se espera con esto contribuir a la discusión en torno a los usos de los animales y sus trayectorias tafonómicas en los valles. La formación de conjuntos arqueofaunísticos en contextos urbanos o semiurbanos implica condiciones específicas en cuanto a los procesos de acumulación, modificación, atrición y remoción de restos óseos, tales como la escala y complejidad de las actividades económicas, el mantenimiento intensivo de los espacios habitados y la influencia del propio asentamiento -durante y después de su ocupación- sobre procesos y agentes no culturales (fauna comensal y fosorial, sedimentación, etc.). Su estudio es pertinente, por lo tanto, a los cambios y diversidad de los modos de vida de las sociedades pasadas. Como objetivos específicos nos propusimos en esta instancia: a) evaluar aspectos vinculados con la subsistencia y la estacionalidad de los conjuntos en Loma Rica; b) determinar si los camélidos presentes en el sitio son de origen doméstico o silvestre; c) establecer si existieron diferencias intrasitio en el uso de los espacios excavados; d) presentar los nuevos datos de un contexto del Período Tardío.

El valle de Santa María o Yocavil (Figura 1) es parte de los Valles Calchaquíes, un sistema de depresiones tectónicas longitudinales dentro de las provincias de Salta, Tucumán y Catamarca (Argentina). Estos valles forman parte del gran área cultural y complejo medioambiental de los Andes Centro-Sur o Meridionales (lat. 15-30 S, aproximadamente) (Lumbreras 1969). Los Andes Centro-Sur cursaron cambios 
socioculturales sustanciales entre los siglos XI y XVI d.C., que definen al Período de Desarrollos Regionales o Tardío del Noroeste Argentino, o Intermedio Tardío de los Andes. Entre los cambios más importantes están la intensificación de la producción de alimentos y la extensión de estilos regionales en cerámica, metales, arte rupestre y textiles. Otra transformación importante durante este período fue la concentración de parte de la población en poblados aglomerados con atributos defensivos y conocidos como pukaras ("fortalezas"), que se extendían sobre riscos o mesetas elevadas de difícil acceso (Nielsen 2001; Tarragó 2011; Álvarez Larrain et al. 2018; Williams et al. 2020).


Figura 1. Ubicación de Loma Rica de Shiquimil en el contexto de otros sitios del Periodo Tardío del valle de Santa María o Yocavil. Imágenes de fondo: Google Terrain (derecha) y Bing Satellite (izquierda).

Los Valles Calchaquíes registran un buen número de sitios proto-urbanos durante este período, como Las Pailas, Quilmes, Tolombón, Los Cardones y El Pichao (Tarragó 2011; Williams 2003; Rivolta 2005; entre otros), muchos de los cuales corresponden al tipo pukara. Sus dimensiones, condiciones de emplazamiento y grados de protección son variables, así como su articulación con áreas habitacionales no defensivas dispersas entre campos de cultivo (Acuto 2007; Baldini 2010; Bugliani 2012; Cantarelli et al. 2014; Maldonado et al. 2014; Coll y Nastri 2015; Palamarczuk et al. 2016; Sampietro Vattuone et al. 2016; Páez y Alé Marinangeli 2016; Álvarez Larraín 2018; Greco 2018; Williams et al. 2020). Algunos pukaras pudieron funcionar efectivamente como refugios fortificados en tiempos de conflicto, pero muchos de ellos muestran evidencias de ocupación permanente (Álvarez Larrain et al. 2018; Nielsen 2018). Asimismo, se ha postulado que el patrón de asentamiento tipo pukara materializa, al menos en el sur de los valles, una jerarquización funcional e ideológica del paisaje vinculada a la emergencia de jefaturas (chiefdoms) (Tarragó 2000). 
Por su parte, el registro zooarqueológico de los Valles Calchaquíes comparte las tendencias generales registradas para el Noroeste argentino: 1) predominio de Camelidae sobre otras familias (ubicuidad y frecuencia relativa); 2) registro, dentro de Camelidae, de especímenes compatibles con vicuña meridional (Vicugna vicugna vicugna, silvestre), guanaco norteño (Lama guanicoe cacsilensis, silvestre) y llama (Lama glama, doméstica) durante la etapa agroalfarera (e.g., Belotti et al. 2012; ; Belotti López de Medina 2011, 2015a, 2015b, 2016, 2017; Izeta 2007a, 2007b; Lanzelotti y Spano 2015; de Guerrero 1968; Mengoni Goñalons 1991, 2013; Pratolongo 2008; Scattolin et al. 2007). Este patrón sugiere una estrategia combinada de caza-ganadería como adaptación al riesgo ambiental, algo propuesto previamente para la región puneña (e.g. Escola 2002; Yacobaccio et al. 1997, 1998).

Durante el período Tardío en particular, el registro parece exhibir alguna diversificación taxonómica (Belotti López de Medina 2015a). No obstante, muchos de los conjuntos conocidos son pequeños y presentan correlaciones significativas entre la diversidad taxonómica (NTaxa familia) y el tamaño de muestra (NISP), lo cual reduce la posibilidad de interpretaciones de grano fino a cualquier escala (Belotti López de Medina 2015a). Una vacancia destacable es la descripción de arqueofaunas de los núcleos elevados de los poblados tipo pukara (e.g. Belotti et al. 2012; Belotti y Bugliani 2019), pertinentes a la organización de las actividades de subsistencia en un paisaje social diferenciado. Por lo tanto, el análisis de la fauna de Loma Rica de Shiquimil permitirá avanzar sobre este problema.

\section{Trabajos de campo en Loma Rica de Shiquimil}

Loma Rica de Shiquimil (Figura 2) se ubica a $2220 \mathrm{msnm}$ y es uno de los sitios más grandes de los Valles Calchaquíes. Además, este es un lugar paradigmático, ya que aquí se condujo la primera expedición arqueológica en el noroeste argentino (Liberani y Hernández 1877). La planicie de cumbre tiene una superficie aproximada de 2,2 ha, pero en todas las laderas también hay construcciones, por lo que la superficie total del sitio se extiende a más de 40 ha. Las habitaciones están construidas en doble pirca con relleno, siendo los lienzos grandes rodados dispuestos en hileras muy parejas; su espesor oscila entre 1,5 y 2,5 m y en algunos casos llega hasta 3 o $4 \mathrm{~m}$, por lo que también pudieron usarse como plataformas o espacios de circulación (Tarragó et al. 1988). Las casi 200 construcciones en la cumbre tienen un alto grado de aglomeración e incluyen grandes patios y estructuras habitacionales menores asociadas, así como dos plazas en los extremos. En las laderas del norte se han registrado varias líneas de muros defensivos y en las del sur y sureste, al menos otros 100 recintos habitacionales concentrados en todos los espacios con pendiente suave o bien aterrazados artificialmente. Los espacios residenciales continúan en la Mesada de Andalhuala-Banda, en donde 111 recintos de similar arquitectura se dispersan entre un mínimo de 80 ha de campos de cultivo (Álvarez Larrain 2016). Los alimentos allí producidos debieron abastecer no sólo al sector poblacional instalado en la Mesada, sino también a los residentes del poblado 
alto. Además de la coincidencia de los mismos estilos arquitectónicos y cerámicos tardíos, los fechados disponibles nos permiten plantear cierto rango de contemporaneidad entre ambos asentamientos (Álvarez Larrain 2016).



Figura 2. Plano de la cumbre de Loma Rica de Shiquimil con ubicación de las unidades de excavación analizadas en este trabajo (UE 1, 2 y 3).

Las excavaciones se realizaron en dos temporadas de campo en 2009 y 2018, abarcando dos conjuntos habitacionales de un patio y estructuras menores asociadas y un espacio abierto sin construcciones (Figura 2). El primero está conformado por la Estructura 29, de forma rectangular de $15 \times 8 \mathrm{~m}$, que se comunica con dos recintos menores, E.27 y E.28, de 6 × 4 y 6,5 x 5,5 m respectivamente. Dentro de E.27 se registró una subestructura de 1,5 x 0,7 m, de funcionalidad indefinida. En 2009 se excavó un sondeo en la E.27 y en 2019 se amplió a una excavación en área extendida abarcando parte de las tres estructuras (Unidad de excavación 1). El único acceso a este conjunto es hacia el sur, en el recinto rectangular, y comunica hacia un área amplia sin construcciones visibles, denominada Espacio III, en donde también se realizó un 
sondeo (Unidad de excavación 2) en 2018. El otro conjunto habitacional está conformado por la Estructura 33, un recinto rectangular de $6 \times 12 \mathrm{~m}$ y la 32, de forma aproximadamente circular de 3,60 × 2,70 m en donde en 2009 se excavó otro sondeo de un cuarto del recinto. En todos los casos la excavación se realizó siguiendo los depósitos naturales, combinados con niveles arbitrarios cada 5 o $10 \mathrm{~cm}$, en caso de no haber cambios en el sedimento. Se zarandeó el 90 \% del sedimento removido con tamiz de malla fina y el $10 \%$ por flotación para recuperar posibles restos vegetales.

\section{Unidad de excavación 1}

Esta unidad de excavación se ubicó en el área de comunicación de las tres estructuras del conjunto habitacional, con el objetivo de tener una muestra comparativa de material de los tres espacios y mantener una visión en conjunto de la estratigrafía. La UE 1 midió $8 \times 8 \mathrm{~m}$ y se excavaron arqueológicamente los sectores intramuros, preservando sin remover el material estructural. Las profundidades máximas alcanzadas fueron variables: en el sector de E.29 el depósito tenía en promedio $50 \mathrm{~cm}$; el pasillo estaba tapado por un relleno de espesor variable, ya que era una estructura en rampa que conecta los dos recintos menores E.27 y E.28, ubicados en una cota inferior que E.29. En estos últimos se excavó hasta un nivel de $120 \mathrm{~cm}$ bajo la superficie, en promedio, ya que la roca de base tiene una fuerte pendiente Norte - Sur, que fue nivelada por los constructores.

El depósito sedimentario en toda la UE es en general de fracción arena-limo, y se encontró muy perturbado por galerías de roedor, muchas de ellas activas. Se pudo observar que este tipo de perturbación es muy frecuente en todo el sitio, por lo tanto, no influyó en contra de nuestra elección de trabajar en esta UE. Luego de los $30 \mathrm{~cm}$ de profundidad el sedimento se torna más fino y compacto. En la E.29 la excavación se completó a los $45 \mathrm{~cm}$, donde aparece una superficie rocosa irregular y consolidada por carbonatos, identificada como la superficie del glacis que caracteriza al cerro.

En las estructuras menores, en cambio, el depósito tenía mayor profundidad. En la E.27 (en las dos temporadas de excavación) se identificó la siguiente estratigrafía:

- Niveles 1, 2 y $3(0-40 \mathrm{~cm})$. Relleno de la estructura por derrumbe y acumulación eólica. Sedimento suelto limo arenoso con gravilla y grava. Muy removido.

- Niveles 4, 5 y $6(40-80 \mathrm{~cm})$. Sedimento más compacto y oscuro por abundantes espículas, artefactos y ecofactos y un fogón en cubeta al finalizar el nivel. Se interpreta como un estrato de ocupación. A los $50 \mathrm{~cm}$ aparecen grandes rocas y los cimientos del muro, aunque el depósito cultural continúa. El piso se pudo apoyar directo sobre la roca y en algunos sectores sobre un sedimento arenoso que pudo ser de nivelación.

- Nivel 7 (80-120 cm). Sedimento arenoso suelto, posible nivelación artificial.

- Nivel 8 (70-120 cm). Rocas consolidadas con carbonatos (superficie de glacis), comienza a aparecer en algunos sectores a los $70 \mathrm{~cm}$ y tiene fuerte pendiente que es nivelada por el nivel 7. 
Por otro lado, en la E.28 la estratigrafía es muy similar:

- Niveles 1, 2 y $3(0-40 \mathrm{~cm})$. Relleno de la estructura por derrumbe y acumulación eólica. Sedimento suelto limo arenoso con gravilla y grava. Muy removido.

- Niveles 4, 5, 6 y 7 (40-100 cm). Sedimento más compacto y oscuro por abundantes espículas, artefactos y ecofactos y dos fogones en cubeta.

- Nivel 8 (100 cm). Roca madre, arenisca disgregada. El piso de ocupación estaba directamente sobre la misma, ya que la base de los fogones estaba cavada en esta roca.

A partir de carbones recuperados en la excavación de 2009 en la Estructura 27, se realizaron dos dataciones radiocarbónicas, una del nivel de ocupación (LP $2212-460 \pm 80$ AP; carbón) y otra del nivel de relleno por debajo del piso y los cimientos del recinto (LP $2431-500 \pm 60 \mathrm{AP}$; carbón). Los valores son similares por lo que se interpretó que la nivelación del terreno fue contemporánea o muy cercana a la ocupación registrada (Greco 2012). Sin embargo, ambos fechados son de carbones que no provienen de rasgos delimitados, los que sí fueron descubiertos en las últimas excavaciones y seguramente proveerán fechados más confiables que pueden replantear esta interpretación.

Unidad de excavación 2

Corresponde a un pequeño sondeo de 50 × $50 \mathrm{~cm}$ que se realizó en un espacio abierto, para evaluar la profundidad del depósito en sectores sin construcciones pero que igualmente pudieron tener múltiples usos en el pasado, como vías de circulación o áreas de actividades al aire libre. En el Espacio III en particular se habían observado abundantes materiales fragmentarios en superficie, por lo cual se consideraba que pudiera tratarse de un área de descarte. La excavación fue realizada por niveles artificiales de $10 \mathrm{~cm}$ hasta una profundidad de $60 \mathrm{~cm}$, en donde continuó apareciendo material cultural, pero el reducido tamaño de la excavación impidió profundizar. A lo largo del sondeo no pudieron observarse cambios estratigráficos, pero la relativamente alta abundancia de hallazgos, especialmente fragmentos de cerámica, de huesos de fauna y carbón, sugieren que se trata de un área de descarte al aire libre.

\section{Unidad de excavación 3}

En la Estructura 32 se excavó un sondeo de 2,3 $\mathrm{m}^{2}$. Desde la superficie y hasta los $50 \mathrm{~cm}$ el sedimento es homogéneo limo-arenoso con pedregullo fino. A esta profundidad comienza a aflorar la roca madre y finaliza la excavación a los $60 \mathrm{~cm}$. No pudo ser distinguida una superficie de ocupación, aunque es probable que se ubicara aproximadamente entre los 40 y $50 \mathrm{~cm}$ de profundidad, coincidente con los cimientos del muro y justo por encima del estrato con pedregullo más grueso y roca madre aflorando. La cantidad de hallazgos es en general mayor en ese nivel, y se destacan abundantes espículas de carbón. Una concentración de estas fue datada en $560 \pm 80 \mathrm{AP}$ (LP 2239; carbón). 


\section{Materiales y Métodos}

Debido a diferencias metodológicas en la etapa de identificación, el carácter no aditivo de medidas como los números mínimos y la imposibilidad de volver a revisar las colecciones, la cuantificación de los resultados no incluye a las arqueofaunas recuperadas en dos cuadrículas excavadas en el año 2009, provenientes de un sector de las estructuras 27 y 32 (nótese en Figura 2 la indicación de excavaciones 2009). Estos conjuntos son pequeños y fueron analizados oportunamente por Belotti López de Medina (2013, 2015a) y colaboradores (Belotti et al. 2012). No obstante, al final de cada acápite se resumen estos datos a efectos de comparar y discutir los presentes resultados.

Los especímenes analizados para este trabajo provienen de las estructuras 27, 28 y 29 y el Espacio III, es decir los recuperados en las excavaciones de 2018. Fueron determinados taxonómica y anatómicamente mediante el uso de colecciones de referencia. Aquellos que no pudieron ser asignados a categorías taxonómicas específicas fueron clasificados por tamaño como: vertebrado pequeño (menos de $1 \mathrm{~kg}$ ), vertebrado mediano (1 a $15 \mathrm{~kg}$ ) y vertebrado grande (más de $15 \mathrm{~kg}$ ). Los restos indeterminados, que no pudieron ser asignados a ninguno de estos grupos, fueron divididos por tamaño $(<1 \mathrm{~cm} ;<2 \mathrm{~cm}$; $<3 \mathrm{~cm} ;<4 \mathrm{~cm} ;<5 \mathrm{~cm})$.

A partir de los datos primarios se calcularon las siguientes medidas: número de especímenes analizados (NSP), especímenes óseos identificados por categoría taxonómica (NISP) y número mínimo de individuos (MNI) (Grayson 1984; Klein y Cruz-Uribe 1984; entre otros). En el caso de los camélidos, que constituyen los restos más abundantes, se construyeron perfiles de partes esqueléticas. Para esto se utilizó, además del NISP y el MNI, el número mínimo de elementos (MNE) estimado por rasgos diagnósticos, el número mínimo de unidades anatómicas identificadas (MAU) y esta misma medida estandarizada (MAU \%) (Binford 1978; Klein y Cruz-Uribe 1984; entre otros). El perfil esquelético de Camelidae fue comparado con el Índice de Utilidad de Carne de Guanaco (Borrero 1990) y el Índice de Secado de Carne (De Nigris y Mengoni Goñalons 2005), a través de correlaciones de Rho de Spearman. Finalmente, la edad de los camélidos fue estimada a partir de la utilización del cronograma de fusión propuesto por Kaufmann (2009) para guanaco.

Se seleccionó una muestra de especímenes apendiculares de Camelidae para su análisis morfométrico. Los criterios de selección fueron que los especímenes conservaran los puntos de medición y que no estuvieran carbonizados ni calcinados. Primero, se midieron los huesos o fragmentos de acuerdo con la guía de Izeta et al. (2012), tomándose tantas medidas como fuera posible de cada espécimen. Luego se clasificaron los especímenes en morfotipos de género o especie a partir de la comparación con medidas de referencia tomadas de la bibliografía o provistas por otros investigadores (Belotti López de Medina 2007, 2013; Cartajena 2002; Elkin 1996; Gasco 2013, 2020; Izeta 2004; Mengoni Goñalons y Elkin comunicación personal;). Se utilizaron dos métodos complementarios 
para este fin: 1) gráficos de dispersión en base a pares de medidas (ancho y profundidad de superficies articulares); 2) análisis de conglomerados UPGMA sobre a matrices de distancia Manhattan (Izeta 2004; Menegaz et al. 1988;).

Con el objetivo de evaluar la integridad de la muestra se consideraron las siguientes variables tafonómicas: meteorización, marcas de roedores, marcas de carnívoros, marcas de raíces, óxido de manganeso, carbonato de calcio, marcas de pisoteo y tipo de fractura (Andrews 1990; Behrensmeyer 1978; Binford 1981; Grayson 1984; Haynes 1980; Johnson 1985; Lyman 1994; Olsen y Shipman 1988; Shipman 1981a). Asimismo, se analizaron los siguientes indicadores de procesamiento en el conjunto óseo: alteración térmica, tipo de fractura y huellas de corte (Binford 1981; David 1990; Johnson 1985). También se registraron atributos de evidencias tecnológicas en los especímenes, siguiendo los criterios macroscópicos propuestos por distintos autores (David 2007; Johnson 1985; Scheinsohn 2010; entre otros).

\section{Resultados}

\section{Estructura taxonómica para el conjunto total}

La muestra total analizada o NSP fue de 1503 especímenes (Tabla 1). Sin embargo, la mayoría de estos $(n=1248)$ corresponde a fragmentos indeterminados de tamaño muy pequeño, siendo más de la mitad menores a $1 \mathrm{~cm}$ de largo. Entre los restos que pudieron ser determinados a algún nivel taxonómico predominan ampliamente los camélidos, con un $83 \%$. A partir de los análisis morfométricos y por remontajes anatómicos, se asignaron ocho especímenes de Camelidae a Vicugna vicugna y un espécimen a Lama sp.; en ambos casos el número mínimo de individuos estimado asciende a uno. En porcentajes mucho menores están representados los roedores, las cáscaras de huevo de Rhea pennata y los armadillos (tres placas y dos huesos postcraneales). También se identificaron dos especímenes de Cervidae y uno de Gastropoda, que no pudieron determinarse a nivel de especie.

Los resultados son similares a los obtenidos sobre las muestras de 2009: Artiodactyla (NISP 15) y Camelidae (NISP 20) representan el $65 \%$ de los restos identificados al menos al nivel de orden (NISP 54) y los segundos conforman el $77 \%$ de los identificados al menos al rango de familia (NISP 26) de estos conjuntos. Otros taxones identificados al menos al rango de orden fueron: roedores (cávidos, ctenómidos e indeterminados, NISP 18) y Chaetophractus vellerosus (NISP 1). También se identificaron 14 fragmentos de valva de molusco.

\section{Representación de partes esqueléticas de Camelidae}

El total de especímenes asignado a Camelidae es de 177. A partir del perfil de partes esqueléticas se determinó un número mínimo de 78 elementos. El número mínimo de individuos es de tres, tanto a partir del ectocuneiforme como de la tibia 
distal. Con respecto a las partes representadas, los valores de MAU \% más altos fueron para el cráneo y el sacro, seguido por la escápula, la epífisis distal de la tibia y algunos huesos articulares. Con valores medios se encuentran las vértebras cervicales, el metatarso y secciones de algunos huesos largos.

\begin{tabular}{|c|c|c|c|c|c|}
\hline Orden/otro & Familia & Género & Especie & NISP & Porcentaje \\
\hline Gastropoda & - & - & - & 1 & 0,47 \\
\hline Artiodactyla & - & - & - & 4 & NA \\
\hline- & Camelidae & - & - & 168 & 78,87 \\
\hline- & - & Lama sp. & - & 1 & 0,47 \\
\hline- & - & - & Vicugna vicugna & 8 & 3,76 \\
\hline- & Cervidae & - & - & 2 & 0,94 \\
\hline- & Chlamyphoridae & - & - & 3 & \multirow{2}{*}{2,35} \\
\hline- & - & - & Ch. vellerosus & 2 & \\
\hline Rodentia & - & - & - & 16 & NA \\
\hline- & Chinchillidae & - & - & 1 & 0,47 \\
\hline- & Ctenomyidae & - & - & 1 & 0,47 \\
\hline- & Cricetidae & - & - & 8 & 3,76 \\
\hline- & Caviidae & - & - & 5 & \multirow{3}{*}{3,76} \\
\hline- & - & Microcavia & - & 1 & \\
\hline- & - & Cavia & - & 2 & \\
\hline- & - & - & R. pennata (c. huevo) & 10 & 4,69 \\
\hline V. mediano & - & - & - & 8 & NA \\
\hline V. grande & - & - & - & 14 & NA \\
\hline Subtotal & & & & 255 & - \\
\hline Indet $<1 \mathrm{~cm}$ & & & & 644 & 51,6 \\
\hline Indet $<2 \mathrm{~cm}$ & & & & 429 & 34,38 \\
\hline Indet $<3 \mathrm{~cm}$ & & & & 148 & 11,86 \\
\hline Indet $<4 \mathrm{~cm}$ & & & & 19 & 1,52 \\
\hline Indet $<5 \mathrm{~cm}$ & & & & 8 & 0,64 \\
\hline Total & & & & 1503 & - \\
\hline
\end{tabular}

Tabla 1. Estructura taxonómica del sitio Loma Rica de Shiquimil. Referencias: NA=no aplica.

Con valores bajos están representados algunos huesos largos, las costillas, la hemipelvis, el resto de las vértebras y las falanges (Tabla 2). La correlación entre el índice de carne y el MAU \% fue no significativa $(R s=0,243 ; \mathrm{p}=0,251)$, en tanto que, para el índice de secado, fue negativa y significativa ( $R s=-0,51, p=0,045)$.

Los conjuntos de E.27 y E.32 analizados en 2009 muestran una mayor frecuencia de especímenes apendiculares (NISP 14), en especial huesos de pies y manos (NISP 11), sobre axiales (NISP 6). El valor MAU \% más alto correspondía, sin embargo, a la vértebra atlas (Belotti López de Medina 2013). 


\section{Estructura de edad de Camelidae}

A partir del análisis de los especímenes óseos se determinaron huesos que parecían corresponder a diferentes categorías de edad. Teniendo en cuenta el cronograma de fusión, se identificó la presencia de un espécimen menor a los tres meses, uno de alrededor de tres meses y uno de 30 a 36 meses. Para el resto de los especímenes sólo pudo estimarse la edad en rangos más amplios, como por ejemplo "menor a 24 meses". Sin embargo, en este grupo están representados, por su tamaño, tanto individuos cría como juveniles. Por otra parte, los molares recuperados estaban muy fragmentados y no pudieron ser utilizados para realizar estimaciones de edad.

En los conjuntos de la excavación 2009 se registraron cinco especímenes no fusionados (cuatro elementos apendiculares de fusión intermedia, 18-36 meses, y un cuerpo de vértebra cervical) y un fragmento de húmero distal fusionado (fusión temprana, 12-18 meses). Combinando los datos de ambas excavaciones, podría argumentarse que están representados al menos individuos perinatos, juveniles y subadultos.

\section{Morfometría}

El análisis de las medidas morfométricas incluyó dos escápulas y seis elementos de la articulación del pie (tibia distal, astrágalo, maleolo, navicular, metatarso proximal y cuboides) (Figura 3). Los huesos de la pata estaban articulados y remontan anatómicamente, por lo que provienen de un mismo animal, algo que permitió subsanar la dificultad de que no se contara con medidas de referencia de todas las especies para cada elemento individual.

A partir de los gráficos bivariados y del análisis de conglomerados se clasificó a una de las escápulas como Lama sp. (guanaco o llama) y a la segunda escápula y los huesos de la articulación del pie como Vicugna vicugna.

\section{Análisis de las Variables Tafonómicas}

Los resultados del análisis de las variables tafonómicas son presentados en la Tabla 3. En relación con la muestra total $(n=1503)$, en el perfil de meteorización predomina el estadio 0 , con escasos especímenes en los estadios 1, 2 y 3 . Por otra parte se registra, aunque en bajos porcentajes, la presencia de carbonato de calcio y óxido de manganeso en la superficie cortical de los restos óseos. Hay una elevada acción de raíces, con un 38 \% , que resultó en una mala preservación de gran parte de la muestra. La acción de roedores y carnívoros es muy baja, en ambos casos con valores menores al $1 \%$. Finalmente, el $97 \%$ de los especímenes se encuentra fracturado. De estos, 116 corresponden a fracturas en estado fresco, 95 de ellas con rasgos asociados como negativos de lascado. El resto, eran de tipo irregular y en la mayoría de los casos, debido a la preservación y al pequeño tamaño de los restos, no pudo determinarse el estado del hueso al momento de ser fracturado. 


\begin{tabular}{|c|c|c|c|c|c|c|c|c|c|c|c|c|c|c|c|}
\hline \multirow{2}{*}{$\begin{array}{c}\text { Unidad } \\
\text { anat }\end{array}$} & \multicolumn{4}{|c|}{ No Fusionado } & \multicolumn{4}{|c|}{ Fusionado } & \multicolumn{3}{|c|}{ Fusión indt } & \multirow[b]{2}{*}{$\mathrm{MNI}$} & \multirow[b]{2}{*}{ MNE } & \multirow[b]{2}{*}{ MAU } & \multirow[b]{2}{*}{ MAU \% } \\
\hline & Izq & Der & $\mathrm{Ax}$ & Indt & Izq & Der & $\mathrm{Ax}$ & Indt & Izq & Der & Indt & & & & \\
\hline Cráneo & - & - & - & - & - & - & - & - & - & - & 2 & 1 & 2 & 2 & 100 \\
\hline V Atlas & - & - & - & - & - & - & - & - & - & - & 1 & 1 & 1 & 1 & 50 \\
\hline V Axis & - & - & - & - & - & - & - & - & - & - & 1 & 1 & 1 & 1 & 50 \\
\hline V Cer & - & - & - & - & - & - & - & - & - & - & 5 & 1 & 5 & 1 & 50 \\
\hline V Lum & - & - & - & - & - & - & 1 & - & - & - & 1 & 1 & 2 & 0,3 & 15 \\
\hline V Tor & - & - & 1 & - & - & - & - & - & - & - & 3 & 1 & 4 & 0,3 & 15 \\
\hline Sacro & - & - & - & - & - & - & 2 & - & - & - & - & 2 & 2 & 2 & 100 \\
\hline Cost & 1 & 3 & - & - & - & 3 & - & - & 2 & - & - & 2 & 9 & 0,3 & 15 \\
\hline Escáp & - & - & - & - & 2 & 1 & - & - & - & - & - & 2 & 3 & 1,5 & 75 \\
\hline Húm Px & - & - & - & - & - & - & - & - & 1 & - & - & 1 & 1 & 0,5 & 25 \\
\hline Húm D & - & - & - & - & - & - & - & - & 1 & - & - & 1 & 1 & 0,5 & 25 \\
\hline Rdcb Px & - & - & - & - & - & 1 & - & - & - & - & 1 & 1 & 2 & 1 & 50 \\
\hline Rdcb D & - & - & - & - & - & - & - & - & - & 1 & - & 1 & 1 & 0,5 & 25 \\
\hline Sesam & - & - & - & - & - & - & - & - & - & - & 2 & 1 & 2 & 0,06 & 3 \\
\hline Piscif & - & - & - & - & - & - & - & - & 1 & 1 & - & 1 & 2 & 1 & 50 \\
\hline Mtcp Px & - & - & - & - & - & - & - & - & 1 & - & - & 1 & 1 & 0,5 & 25 \\
\hline Hpelvis & - & - & - & - & - & - & - & - & 1 & - & - & 1 & 1 & 0,5 & 25 \\
\hline Fém Px & - & 1 & - & - & - & - & - & - & - & - & - & 1 & 1 & 0,5 & 25 \\
\hline Fém D & - & 1 & - & - & - & - & - & - & - & - & 1 & 1 & 2 & 1 & 50 \\
\hline Fém Dt & - & - & - & - & 1 & - & - & - & - & - & - & 1 & 1 & 0,5 & 25 \\
\hline Tibia Px & - & - & - & - & \begin{tabular}{|l|}
1 \\
\end{tabular} & 1 & - & - & - & - & - & 1 & 2 & 1 & 50 \\
\hline Tibia D & - & - & - & - & - & 1 & - & - & - & - & - & 1 & 1 & 0,5 & 25 \\
\hline Tibia Dt & - & - & - & - & - & 3 & - & - & - & - & - & 3 & 3 & 1,5 & 75 \\
\hline Mtts Px & - & - & - & - & - & - & - & - & - & 1 & 1 & 1 & 2 & 1 & 50 \\
\hline Mtts D & - & - & - & - & - & - & - & - & - & 1 & 1 & 1 & 2 & 1 & 50 \\
\hline Navic & - & - & - & - & - & - & - & - & 1 & 1 & - & 1 & 2 & 1 & 50 \\
\hline $\mathrm{Cub}$ & - & - & - & - & - & - & - & - & - & 1 & - & 1 & 1 & 0,5 & 25 \\
\hline Ectoc & - & - & - & - & - & - & - & - & - & 3 & - & 3 & 3 & 1,5 & 75 \\
\hline Fibular & - & - & - & - & - & - & - & - & - & 1 & - & 1 & 1 & 0,5 & 25 \\
\hline Astrág & - & - & - & - & - & - & - & - & - & 2 & - & 2 & 2 & 1 & 50 \\
\hline Mtpd D & - & - & - & 2 & - & - & - & 1 & - & - & - & 1 & 3 & 0,75 & 37,7 \\
\hline Mtpd Ds & - & - & - & 1 & - & - & - & 1 & - & - & - & 1 & 2 & 1 & 50 \\
\hline $1^{\circ} \mathrm{Fal}$ & - & - & - & 1 & - & - & - & 1 & - & - & 2 & 2 & 4 & 0,5 & 25 \\
\hline $2^{\circ} \mathrm{Fal}$ & - & - & - & 1 & - & - & - & 1 & - & - & 1 & 2 & 3 & 0,4 & 20 \\
\hline $3^{\circ} \mathrm{Fal}$ & - & - & - & - & - & - & - & - & - & - & 3 & 1 & 3 & 0,4 & 20 \\
\hline
\end{tabular}

Tabla 2. Perfil de partes esqueléticas de Camelidae para la muestra total, cuantificado como número mínimo de elementos (MNE), individuos (MNI) y unidades anatómicas (MAU y MAU \%). Referencias: Px=proximal, $\mathrm{D}=$ diáfisis, $\mathrm{Ds}=$ distal. 


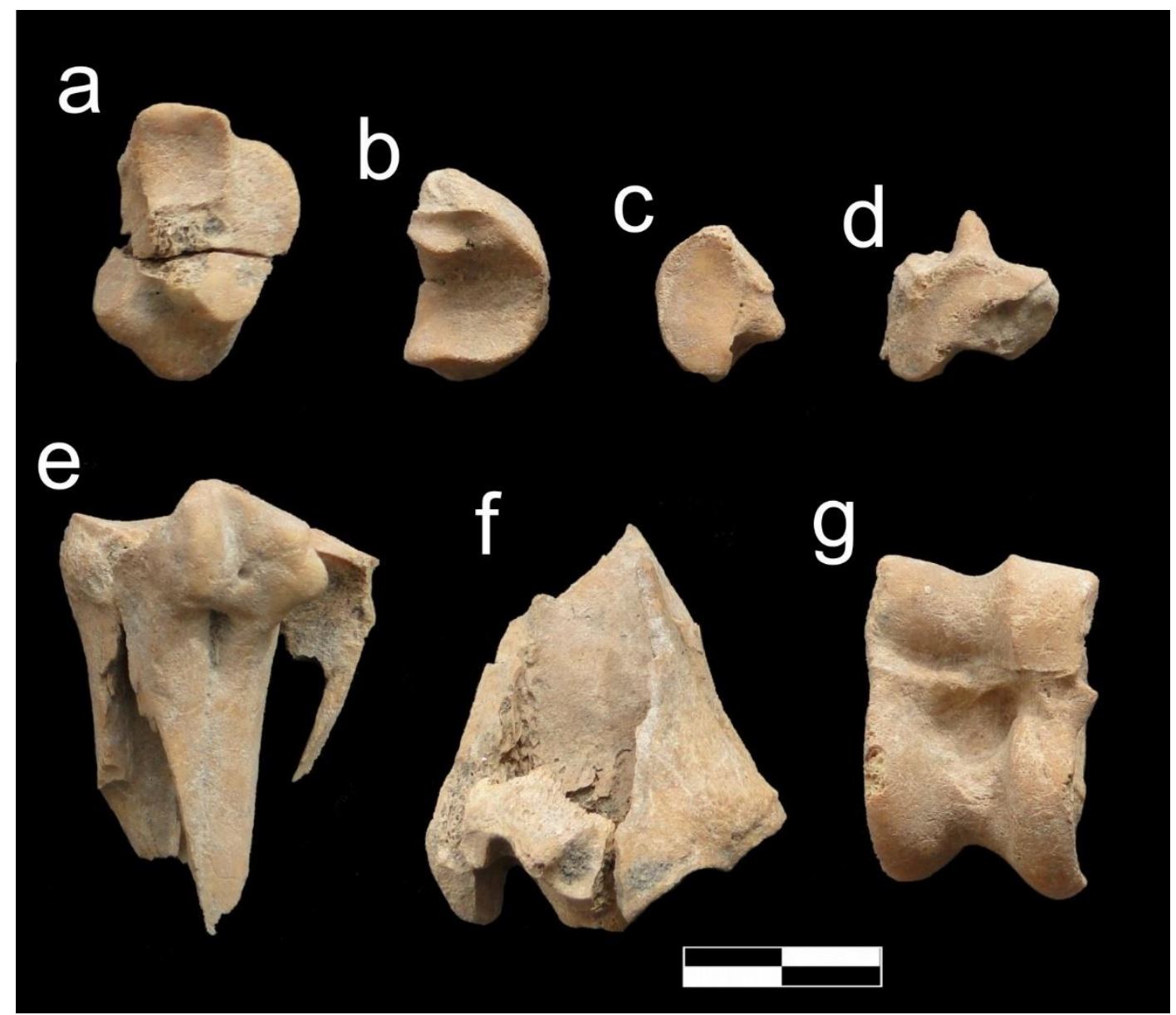

Figura 3. Especímenes de Vicugna vicugna que remontan anatómicamente. a) cuboides, b) navicular, c) ectocuneiforme, d) fibular, e) metatarso proximal, f) tibia distal, g) astrágalo.

Considerando los restos que pudieron ser asignados a alguna categoría taxonómica, los camélidos y los roedores fueron aquellos para los cuales se registraron mayor cantidad de especímenes (NISP: 177 y 34, respectivamente). Por este motivo, se cuantificaron las variables tafonómicas para ambos grupos por separado, para evaluar si estos conjuntos tuvieron historias tafonómicas diferentes (Tabla 3). Los valores para los camélidos son similares al conjunto total, con excepción del perfil de meteorización, que es ligeramente más avanzado. Por otra parte, la acción de raíces alcanza valores de $73 \%$. Otro aspecto destacable es que, a pesar de haber excluido a los restos indeterminados, la muestra presenta igualmente una elevada fragmentación, con casi $90 \%$ de los especímenes incompletos.

En el caso de los roedores, se destaca la ausencia de meteorización. No se registra carbonato de calcio $\mathrm{u}$ óxido de manganeso en la superficie cortical de los restos, aunque sí tienen un elevado porcentaje de acción de raíces. En general, su preservación es muy buena y su coloración es diferente a la del resto de los huesos de la muestra total. Estas evidencias, junto con la ausencia de meteorización y depositaciones químicas, indicarían que los restos correspondientes a este Orden tuvieron un ingreso posterior al sitio. 


\begin{tabular}{|c|c|c|c|c|c|c|}
\hline & \multicolumn{2}{|c|}{ Conjunto total } & \multicolumn{2}{c|}{ Camelidae } & \multicolumn{2}{c|}{ Rodentia } \\
\hline Variables & $\mathbf{N}$ & $\%$ & $\mathbf{N}$ & $\%$ & $\mathbf{N}$ & $\%$ \\
\hline Meteorización (E0) & 1413 & 94,01 & 149 & 84,18 & 34 & 100 \\
\hline Meteorización (E1) & 50 & 3,33 & 13 & 7,34 & - & - \\
\hline Meteorización (E2) & 35 & 2,33 & 12 & 6,78 & - & - \\
\hline Meteorización (E3) & 5 & 0,33 & 3 & 1,69 & - & - \\
\hline Meteorización (E4) & - & - & - & - & - & - \\
\hline Meteorización (E5) & - & - & - & - & - & - \\
\hline Carbonato de calcio & 90 & 5,99 & 12 & 6,78 & - & - \\
\hline Óxido de manganeso & 70 & 4,66 & 11 & 6,21 & - & - \\
\hline Raíces & 572 & 38,06 & 129 & 72,88 & 27 & 79,41 \\
\hline Carnívoros & 2 & 0,13 & 1 & 0,56 & 1 & 2,94 \\
\hline Roedores & 3 & 0,20 & 2 & 1,13 & - & - \\
\hline Fracturas & 1461 & 97,21 & 159 & 89,83 & 19 & 55,88 \\
\hline
\end{tabular}

Tabla 3. Variables tafonómicas para el conjunto total y para Camelidae y Rodentia.

Estos resultados son similares a los obtenidos antes sobre los conjuntos de los recintos 27 y 32 excavados en 2009. Primero, sólo el 10,9 \% (NSP 21) de los especímenes de vertebrados grandes de aquellos conjuntos (NSP 193, categorías 3 y 4 de tamaño corporal sensu Izeta 2007a) presenta algún indicio de meteorización. Se registraron entonces también marcas de raíces (NSP 3), roedores (NSP 1) y carnívoros (NSP 4). Asimismo, el 92 \% (NSP 76) de los especímenes de vertebrados grandes estaba fragmentado. Estas similitudes son de esperar ya que, no solo los conjuntos provienen del mismo sitio, sino que en el caso de E.27 estamos tratando con muestras de las mismas unidades estratigráficas.

Las variables tafonómicas fueron también consideradas en relación con las unidades de excavación. Como se observa en la Tabla 4, no hay diferencias significativas en cuanto a los patrones relevados, salvo por la ausencia de óxido de manganeso en el Espacio III.

En relación con las evidencias de procesamiento en el conjunto, se registró la presencia de huellas de corte, alteración térmica, fracturas intencionales $y$ modificaciones tecnológicas. Con respecto a las huellas de corte, estas se identificaron en 53 especímenes. Uno de ellos corresponde a Chlamyphoridae (huella de fileteo en vértebra lumbar), en tanto que el resto fueron asignados a Camelidae o vertebrados indeterminados. En el caso de Camelidae, la mayoría de las actividades registradas fueron asignadas a fileteo $(n=24)$, seguidas por desarticulación $(n=4)$ y cuereo $(n=3)$. 


\begin{tabular}{|c|c|c|c|c|c|c|c|c|c|c|c|c|}
\hline & \multicolumn{2}{|c|}{ E.27 } & \multicolumn{2}{|c|}{ Sub.27 } & \multicolumn{2}{c|}{ E.28 } & \multicolumn{2}{c|}{ E.29 } & \multicolumn{2}{c|}{ Pas. } & \multicolumn{2}{c|}{ Esp. III } \\
\hline Variables & $\mathbf{N}$ & $\%$ & $\mathbf{N}$ & $\%$ & $\mathbf{N}$ & $\mathbf{\%}$ & $\mathbf{N}$ & $\%$ & $\mathbf{N}$ & $\mathbf{\%}$ & $\mathbf{N}$ & $\mathbf{\%}$ \\
\hline Meteorización (E0) & 474 & 95,76 & 96 & 95,05 & 562 & 92,89 & 83 & 85,57 & 60 & 92,31 & 138 & 98,57 \\
\hline Meteorización (E1) & 14 & 2,83 & 4 & 3,96 & 22 & 3,64 & 6 & 6,19 & 2 & 3,08 & 2 & 1,43 \\
\hline Meteorización (E2) & 6 & 1,21 & - & - & 19 & 3,14 & 7 & 7,22 & 3 & 4,62 & - & - \\
\hline Meteorización (E3) & 1 & 0,2 & 1 & 0,99 & 2 & 0,33 & 1 & 1,03 & - & - & - & - \\
\hline Meteorización (E4) & - & - & - & - & - & - & - & - & - & - & - & - \\
\hline Meteorización (E5) & - & - & - & - & - & - & - & - & - & - & - & - \\
\hline Carbonato de calcio & 21 & 4,24 & 2 & 1,98 & 45 & 7,44 & 13 & 13,40 & 6 & 9,23 & 3 & 2,14 \\
\hline Óxido de manganes0 & 14 & 2,83 & 3 & 2,97 & 36 & 5,95 & 9 & 9,28 & 8 & 12,31 & - & - \\
\hline Raíces & 210 & 42,42 & 39 & 38,61 & 224 & 37,02 & 50 & 51,55 & 13 & 20 & 36 & 25,71 \\
\hline Carnívoros & 1 & 0,2 & - & - & 1 & 0,17 & - & - & - & - & - & - \\
\hline Roedores & 1 & 0,2 & - & - & 2 & 0,33 & - & - & - & - & - & - \\
\hline Fractura & 487 & 98,38 & 98 & 97,03 & 583 & 96,36 & 92 & 94,85 & 64 & 98,46 & 137 & 97,86 \\
\hline
\end{tabular}

Tabla 4. Variables tafonómicas por unidad de excavación. Referencias: E=estructura, $\mathrm{Sub}=$ subestructura, Esp=espacio, Pas=pasillo.

Con respecto a las fracturas intencionales, se identificaron 95 fracturas helicoidales y nueve longitudinales, todas ellas con rasgos asociados tales como muescas y negativos de lascado, entre otros. Si bien la mayoría de las fracturas antrópicas fueron efectuadas sobre huesos largos de camélidos, también se identificaron para la $1^{\circ}$ y $2^{\circ}$ falange. Finalmente, fracturas frescas, aunque sin rasgos asociados, pudieron ser reconocidas en algunas vértebras y huesos del autopodio de Camelidae.

La presencia de alteración térmica fue registrada en restos de vertebrados indeterminados y especímenes de Camelidae. Se trata de restos carbonizados $(n=44)$ y calcinados $(n=170)$, gran parte de los cuales correspondían a fragmentos pequeños.

Se identificaron cinco especímenes con evidencias tecnológicas, cuatro de ellos correspondientes a restos óseos y uno a un Gastropodo (Tabla 5 y Figura 4). En el caso de los óseos, dos pudieron ser asignados a Camelidae y dos a vertebrado indeterminado. Estos corresponden a huesos largos y presentan pulido y estrías en sus extremos activos o algunos de sus bordes. Fueron confeccionados sobre segmentos de diáfisis, uno de ellos obtenido a partir de una fractura fresca (LRS.F.1250) y en los demás casos no pudo determinarse. Con respecto a los grupos morfológicos, dos son indeterminados, uno corresponde a un bisel (Figura 4d) y otro a una punta (Figura 4c). En este último caso, el espécimen presenta sección circular y podría tratarse de un punzón. En el caso del Gastropodo, este exhibe algunos sectores pulidos y evidencias de que el ápice y parte del canal 
sifonal fueron seccionados, posiblemente para ser utilizado como pendiente. Asimismo, se observa un corte que podría haber sido producto de este proceso (Figura 4e).

\begin{tabular}{|c|c|c|c|c|c|}
\hline Sigla & Unidad & Largo (mm) & Ancho (mm) & Espesor (mm) & GM \\
\hline LRS.F.1148 & E.29 & 66,55 & 13,97 & 4,81 & bisel \\
\hline LRS.F.1194 & E.27 & 85,15 & 14,44 & 3,75 & indet \\
\hline LRS.F.1231 & Sub.27 & 56,86 & 6,28 & 4,10 & punta \\
\hline LRS.F.1250 & E.28 & 34,90 & 11,69 & 5,07 & indet \\
\hline LRS.F.1147 & E.27 & 17,94 & 10,72 & NA & NA \\
\hline
\end{tabular}

Tabla 5. Especímenes con evidencias tecnológicas del sitio Loma Rica de Shiquimil. Referencias: $\mathrm{NA}=$ no aplica, $\mathrm{GM}=$ grupo morfológico.

No se registraron marcas de procesamiento en los conjuntos de 2009 y las fracturas de huesos largos son de tipo longitudinal sobre hueso seco. Debe recordarse que estos eran conjuntos muy pequeños y poco representativos. El $31 \%$ de los especímenes exhibía alteraciones térmicas.

\section{Resultados por unidades de análisis}

Teniendo en cuenta las unidades de análisis propuestas para el sitio, la muestra fue subdividida con el objetivo de evaluar si estos espacios fueron utilizados diferencialmente. En la Tabla 6 pueden observarse los datos separados por subconjuntos, aunque algunos de los taxones fueron agrupados para facilitar su presentación. En este caso sí fueron agregados los hallazgos de 2009 y 2018, por lo cual los totales son diferentes a las tablas anteriores. Se observa que en todas las unidades de análisis predominan los fragmentos indeterminados, seguidos por los camélidos. La mayor diversidad corresponde a las estructuras 27 y 28, que además tienen las muestras más grandes, en tanto que el Pasillo tiene la menor cantidad de restos. No existe tampoco un patrón diferencial en cuanto a las evidencias de procesamiento, aunque hay un predominio de alteración térmica en las estructuras 27 y 28 . Otro punto a tener en cuenta es que la mayor cantidad de roedores en la estructura 28 podría indicar mayor perturbación. Por otra parte, en cuanto a las partes de camélidos, en todas las unidades hay diferentes unidades y edades representadas, aunque es en la 28 en la cual se registró el pie articulado de vicuña (Tabla 6). 


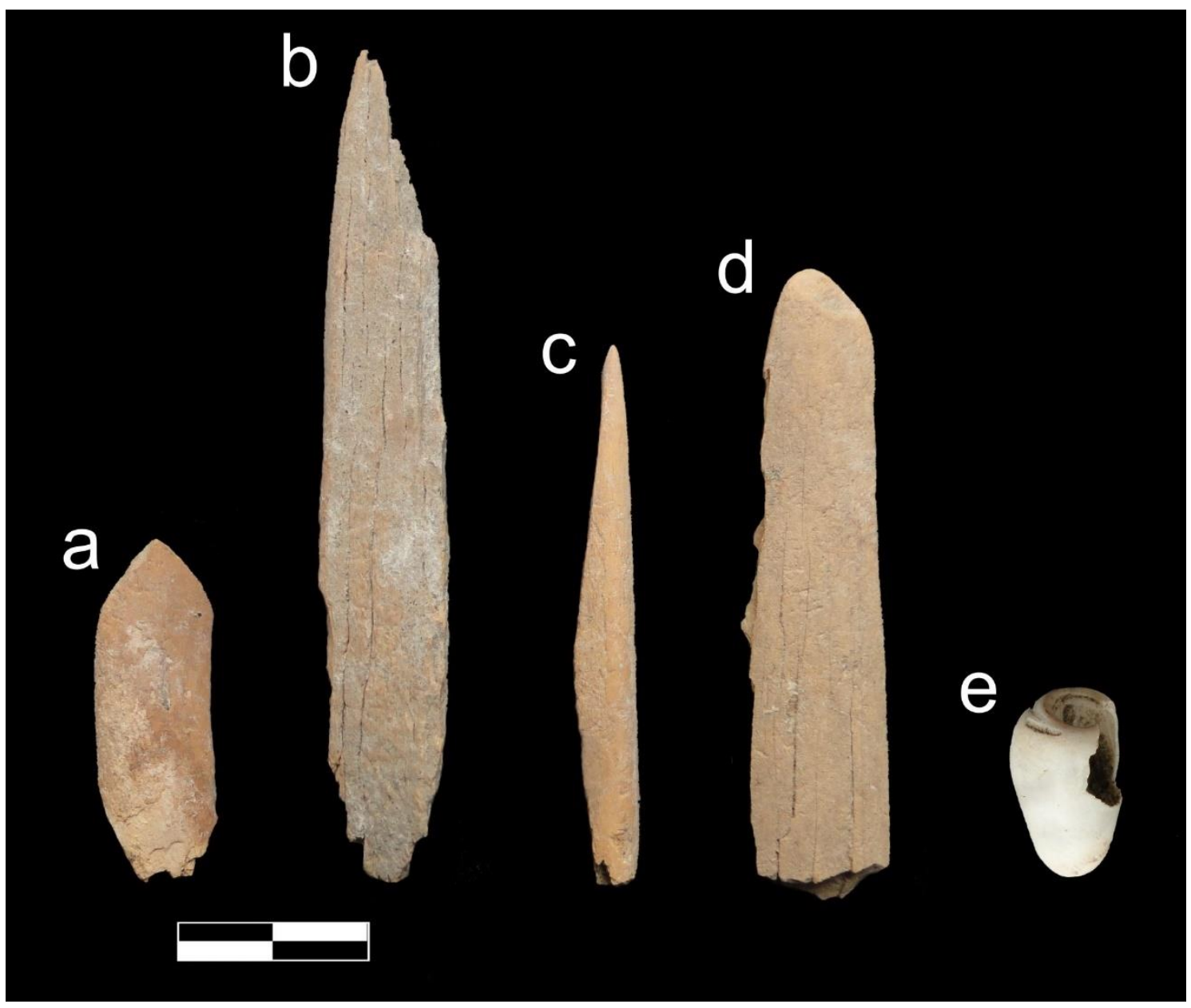

Figura 4. Especímenes con evidencias tecnológicas del sitio Loma Rica de Shiquimil. a) LMS.F.1250; b) LMS.F.1194; c) LMS.F.1231; d) LMS.F.1148; e) LRS.F.1147.

\section{Discusión y Conclusiones}

Los resultados del análisis de las variables tafonómicas indican que el conjunto no habría estado expuesto por largos períodos de tiempo. El entierro de los materiales habría sido favorecido, posiblemente, por la acción de raíces, que generó una mala preservación de la superficie cortical de los restos. Sobre este punto, vale la pena observar que el sitio fue desmalezado con objetivos turísticos en los años 80, pudiendo generarse movimientos de suelo en los niveles más superficiales y posterior recomposición de la flora y fauna local, cuyo efecto sobre el conjunto aún desconocemos. Por otra parte, la presencia de las depositaciones químicas indica que en algún momento el ambiente tuvo humedad, con presencia de filtración de aguas carbonatadas, con baja circulación o encharcamiento (López González et al. 2006). Al considerar por separado a los camélidos y los roedores, algunos valores se modifican, aunque los primeros mantienen tendencias similares al conjunto general. Los resultados de las variables analizadas para el Orden Rodentia apoyan la idea de que estos restos tuvieron un ingreso posterior al sitio. Esto también se condice con la ausencia de evidencias de procesamiento antrópico para estos animales y el registro de cuevas durante la excavación. 


\begin{tabular}{|c|c|c|c|c|c|c|c|}
\hline Unidad de Excavación & \multicolumn{5}{|c|}{ UE1 } & UE2 & UE3 \\
\hline Taxón / Procedencia & E.27 & Sub.27 & E.28 & E.29 & Pas. & Esp. III & E.32 \\
\hline Vertebrado grande & 13 & - & 4 & 1 & - & - & - \\
\hline Vertebrado mediano & 1 & 1 & 4 & 1 & 1 & - & - \\
\hline Artiodactyla & 15 & - & - & - & - & - & - \\
\hline Chlamyphoridae & 2 & - & 3 & - & - & 1 & - \\
\hline Rodentia & 21 & 2 & 20 & 3 & 1 & 1 & 4 \\
\hline Camelidae & 82 & 12 & 61 & 22 & 7 & 11 & 2 \\
\hline Cervidae & - & - & 2 & - & - & - & - \\
\hline Rhea pennata $(\mathrm{c}$. huevo $)$ & 5 & - & 4 & - & - & 1 & - \\
\hline Mollusca & 5 & - & - & - & - & - & 2 \\
\hline Gastropoda & 4 & - & - & - & - & - & 4 \\
\hline Indet & 908 & 86 & 507 & 70 & 56 & 126 & 145 \\
\hline Total & 1156 & 101 & 605 & 97 & 65 & 140 & 157 \\
\hline Superficie excavada $\left(\mathrm{m}^{2}\right)$ & 7,9 & 1 & 17,4 & 12 & 2 & 0,5 & 2,3 \\
\hline Densidad (especímenes $\left./ \mathrm{m}^{2}\right)$ & 146,32 & 101 & 34,77 & 8,08 & 32,5 & 280 & 68,26 \\
\hline
\end{tabular}

Tabla 6. NISP por categoría taxonómica y unidad de excavación. Referencias: E=estructura, $\mathrm{Sub}=$ subestructura, Esp=espacio, Pas=pasillo.

En relación con la comparación de los resultados tafonómicos por estructura, no se observan diferencias significativas, aunque se destaca la ausencia de óxido de manganeso en el Espacio III. Si bien la muestra es pequeña, podría considerarse que, al ser este un lugar abierto, no se habrían dado las condiciones necesarias, como son el encharcamiento o circulación de agua de leve intensidad (López González et al. 2006), para la precipitación de este mineral y la consecuente tinción de los huesos, lo cual sí podría haber sucedido es las estructuras.

Un aspecto destacado es la elevada fragmentación del conjunto. En este punto es importante mencionar que parte de esta tiene un origen antrópico, como se discutirá más adelante. Sin embargo, para un gran porcentaje de los restos, sobre todo aquellos de tamaño muy pequeño, no pudo determinarse el origen de las fracturas. Es necesario tener en cuenta que las estructuras analizadas constituyen áreas de actividad, por lo cual serían sectores limpiadas de manera recurrente (Tani 1995). Los residuos más pequeños podrían haber estado sometidos a pisoteo $\mathrm{y}$ haber sido fracturados, especialmente aquellos quemados (Miller et al. 2010). Sin embargo, aunque su acción no pueda descartarse, no se identificaron marcas de este proceso en los restos analizados. 
La estructura taxonómica de Loma Rica de Shiquimil es similar a la registrada para otros sitios de los valles Calchaquíes (e.g. Belotti López de Medina 2015a, 2015b; Izeta 2007a; Mengoni Goñalons 2013; Pratolongo 2008) y del Noroeste argentino en general, siendo Camelidae la familia predominante. En porcentajes mucho menores se encuentran las cáscaras de huevo de ñandú, los armadillos y Cervidae. En el caso de los camélidos, es importante destacar que pudo determinarse la presencia de al menos un individuo correspondiente al género Lama y otro a vicuña. En cuanto al de mayor tamaño, podría corresponder a guanaco o llama.

Las llamas se criaron para su consumo o como animales de carga (e.g. Izeta y Cortés 2006) y producción de fibra. En este caso es posible que los restos correspondan a animales que se criaron y mantuvieron vivos en cercanías del sitio, como parte de un sistema de producción pastoril o agro-pastoril. Este aspecto deberá ser cotejado al ampliarse la muestra de estudio, así como con el análisis de rasgos arquitectónicos relacionados a esta actividad, como corrales, que hasta ahora no han sido identificados. Por otra parte, el registro de vicuña indica actividades de caza de camélidos silvestres, aunque por la escasa muestra no puede determinarse en qué grado esta actividad complementó al pastoralismo. La presencia de vicuña, fuera de su distribución actual, es un hecho observado repetidamente en otros sitios de los valles (Belotti 2015a; Izeta 2008).

Ampliando la mirada a un nivel microregional, la evidencia de Loma Rica se suma a estudios previos en la Mesada de Andalhuala-Banda de contextos Formativos (Soria 2 R1 y R2, Unidad Arquitectónica 11) y Tardíos (Unidades Arquitectónicas 96 y 113) (Álvarez Larrain 2016; Álvarez Larrain et al. 2016; Belotti López de Medina 2011). En todos estos conjuntos Camelidae es la familia más abundante o la única identificada, si bien sólo los conjuntos de Soria 2 presentan un volumen abundante de fauna y se pudo determinar la presencia de los morfotipos de Lama sp., L. guanicoe, L. glama y V. vicugna. Otros taxones registrados en Soria 2 son Hippocamelus antisensis, Caviidae, Chinchillidae y Chaetophractus. Los datos de Loma Rica sugieren una similitud global de los procesos culturales y naturales de acumulación de fauna, empezando por la propia diversidad taxonómica del entorno. Esto se repite si llevamos la escala a la etapa agroalfarera de los valles Calchaquíes (Belotti López de Medina2015a, 2015b; Izeta 2007a, 2007b; Izeta et al. 2009; Mengoni Goñalons 2013).

En relación con el perfil de partes esqueléticas, se observa la presencia de gran variedad de unidades anatómicas, aunque ninguna predomina de manera significativa por sobre otra. Tampoco se observan diferencias entre las frecuencias de restos del esqueleto axial y el apendicular, como se ha registrado, por ejemplo, para casos de pastores actuales (Yacobaccio et al. 1998). Además, la correlación entre el índice de carne no fue significativa, indicando que no hay una relación entre las unidades presentes y su valor cárnico. Por otra parte, la correlación con el índice de secado fue negativa y significativa, lo cual sugiere la posibilidad de que los elementos ausentes puedan haber sido seleccionados para su conservación y posterior consumo. Ambos 
resultados deben tratarse con cautela ya que la muestra es pequeña. Más allá de esto, la alta fragmentación de los restos en Loma Rica de Shiquimil, junto con el registro de la elevada frecuencia de fracturas helicoidales, que incluyen la $1^{\circ}$ y $2^{\circ}$ falange, está indicando un uso intensivo de los camélidos, algo observado también en otros sitios. Una posibilidad es que el procesamiento intensivo y las conductas de limpieza de los recintos tengan una incidencia mayor a otros procesos tafonómicos respecto de los perfiles anatómicos. No obstante, debemos observar que estos problemas se repiten en conjuntos de diversos períodos y en contextos que van de pisos de ocupación a basurales (e.g. Belotti López de Medina 2011, 2015b; Izeta 2007a ; Pratolongo 2008), con alta fragmentación y correlaciones no significativas o tendencias opuestas entre huesos largos y no largos.

Entre las actividades de origen antrópico relevadas para los camélidos está el cuereo, la desarticulación y el fileteo, así como el registro de instrumentos óseos, indicando uso de cuero, carne y huesos como materia prima. En relación con esto último, los instrumentos recuperados presentan escasa formatización y estandarización. Estos artefactos no muestran una elaboración planificada. En cuanto a su uso, podrían haber sido empleados en actividades textiles, como el caso del espécimen con morfología de punzón, o también en la talla lítica, como el ítem con morfología de bisel, que podría haber sido utilizado como retocador.

La elevada fragmentación de la muestra, en la cual hay representadas fracturas frescas, coincide con los modelos planteados para la extracción de grasa ósea (Church y Lyman 2003; Outram 2001). Este patrón ha sido observado también en otros sitios de los Valles Calchaquíes (e.g. Belotti 2011; Izeta 2007a). En este sentido, las evidencias sugieren un uso integral e intensivo de los camélidos para Loma Rica de Shiquimil.

En relación con la estructura etaria, la presencia de individuos de distintas edades indica el ingreso de los animales al menos entre fines de la primavera y el verano, lo que puede ser también un indicador del lapso de ocupación anual mínima de los sitios, que es el período de máxima productividad del entorno y de apareamiento y parición de los camélidos en el NOA (Vilá 2012). Por otra parte, si bien para el resto de los elementos las edades pudieron estimarse en rangos amplios, el tamaño de los elementos indica la presencia tanto de individuos cría como juveniles. Asimismo, debe mencionarse el registro de fragmentos de huevo de ñandú, cuya puesta tiene lugar entre agosto y octubre (Sarasqueta 1990). En síntesis, las evidencias disponibles, aunque son escasas, sugieren que el sitio fue ocupado en diferentes momentos del año, tal vez de manera permanente, y no sólo como refugio en momentos de conflicto intercomunitario.

Con respecto al análisis intrasitio, el tamaño y la fragmentación de la muestra no permitió identificar diferencias de uso entre los distintos recintos excavados. Sólo puede mencionarse la menor cantidad de materiales en el Pasillo y la mayor variabilidad en las estructuras 27 y 28 . No obstante, resulta interesante que el Espacio 
III, el sondeo en un área abierta, tenga la mayor densidad de hallazgos. En cuanto a los recintos, el 27 es el de mayor densidad y contrasta con E.28 y E.32; siendo estructuras comparables en forma y tamaño podría asumirse que tienen funcionalidades similares, pero la fauna podría reflejar usos diferentes. En la subestructura del E.27 también es alta la densidad, es un pequeño espacio de funcionalidad indefinida, tal vez algún tipo de depósito. E.29 presenta la menor densidad relativa y sería el único sector, por su morfología, asignado a la categoría de patio. Estos datos cobrarán más sentido cuando se comparen otras líneas de evidencia.

Como conclusión, el conjunto de Loma Rica de Shiquimil aporta nuevos datos que permiten discutir el uso de los animales en el Período Tardío. En coincidencia con lo observado por otros autores, se destaca el predominio de camélidos. En general, estos fueron utilizados de forma integral e intensiva, resultando en conjuntos muy fragmentados y con escasa representación de otros taxones. Los huesos de los animales que ingresaron al sitio registran varias etapas de procesamiento, que incluyeron el cuereo, desarticulación y fileteo, así como el uso de algunos elementos como materia prima. Estas evidencias, junto con los perfiles de partes esqueléticas, podrían indicar que parte de estas actividades se efectuaron en el sitio, posiblemente en distintos momentos del año.

Agradecimientos: Las tareas de campo de 2018 fueron posibles gracias al financiamiento del proyecto de investigación ANPCYT-PICT 2016-3319 (dirigido por Catriel Greco) y al apoyo logístico de la Municipalidad de San José (Catamarca). Se contó con la autorización de la Comunidad Originaria Ingamana y la Dirección Provincial de Antropología de Catamarca. Queremos agradecer a la familia Cáceres de Entre Ríos y también a estudiantes, colegas y voluntarias/os, cuya colaboración fue fundamental para llevar adelante esta investigación.

\section{Bibliografía citada}

Acuto, F. A.

2007 Fragmentación vs. integración comunal: repensando el Período Tardío del Noroeste Argentino. Estudios Atacameños 34: 71-95.

Álvarez Larrain, A.

2016 Paisajes agroalfareros del primer y segundo milenio D.C. en la Mesada de Andalhuala Banda (Yocavil, Noroeste Argentino). Ñawpa Pacha 36(2): 207-217.

Álvarez Larrain, A.

2018 Chacras of the Pukara: The Late Occupation (Tenth-Sixteenth Centuries) of Mesada De Andalhuala Banda, Yocavil (Catamarca, Argentina). Political Landscapes of the Late Intermediate Period in the South-Central Andes. The Pukaras and their hinterland (ed. por A. Álvarez Larrain y C. Greco), (pp. 61-94). Springer, Cham. 
Álvarez Larrain, A., R. C. Spano y M. S. Grimoldi

2016 Soria 3: Nuevas evidencias de la ocupación aldeana temprana en Yocavil, Noroeste argentino. Un ejercicio interpretativo. Revista Española de Antropología Americana 46: 219-239.

Álvarez Larrain, A., C. Greco y F. Wynveldt

2018 Introduction. Political Landscapes of the Late Intermediate Period in the SouthCentral Andes. The Pukaras and their hinterland (ed. por A. Álvarez Larrain y C. Greco), pp. 1-9. Springer, Cham.

Andrews, P.

1990 Owls, Caves and Fossils. Natural History Museum, Londres.

Baldini, L.

2010 El espacio cotidiano. Las casas prehispánicas tardías en el valle Calchaquí, Salta. El hábitat prehispánico. Arqueología de la arquitectura y de la construcción del espacio organizado (ed. por E. Albeck, M. C. Scattolin y M. A. Korstanje), pp. 53-75. M. FHyCS, UNJu, San Salvador de Jujuy.

Behrensmeyer, A. K.

1978 Taphonomic and Ecologic Information from Bone Weathering. Paleobiology 4: 150-162.

Belotti López de Medina, C. R.

2007 Zooarqueología del sitio Soria 2 (Departamento de Santa María, Provincia de Catamarca) y estudio comparativo del registro zooarqueológico del sur de los valles Calchaquies, para los Períodos Formativo y Desarrollos Regionales (siglos I A. C. a XV D. C.). Tesis de Licenciatura Inédita. Facultad de Filosofía y Letras, Universidad de Buenos Aires.

2011 Zooarqueología del sitio formativo Soria 2, valle de Yocavil (Catamarca), siglo I d.C. Revista del Museo de Antropología 4: 3-16.

2013 Usos económicos y rituales de la fauna en la región valliserrana del Noroeste argentino entre los inicios del periodo Temprano y hasta la conquista Inka (ca. 600 AC - 1600 DC): Zooarqueología del valle de Yocavil (Catamarca), centro y norte del Valle Calcchaquí (Salta) y la Quebrada de Humahuaca (Jujuy). Tesis Doctoral Inédita. Facultad de Filosofía y Letras, Universidad de Buenos Aires.

2015a Desigualdad e intensificación de la subsistencia en el Valle de Yocavil (Catamarca y Tucumán, Argentina) entre los siglos I aC y XVI dC. Relaciones de la Sociedad Argentina de Antropología 40(1): 73-100.

2015b Subsistence and Economy at the Calchaquí Valley (Salta, Argentina) during the Regional Developments Period (ca. 1000-1430 AD): Zooarchaeology of Las Pailas locality. Journal of Archaeological Science: Reports 4: 461-476.

2016 Zooarqueología de un centro administrativo inca del Valle de Yocavil (Catamarca): El Tambo de Punta de Balasto. Revista del Museo de Antropología 9(2): 1727. 
Belotti López de Medina, C. R.

2017 Nuevos datos zooarqueológicos de Rincón Chico 15, Valle de Yocavil (Catamarca, Argentina). Arqueología 23: 99-107.

Belotti, C., E. Gaal, C. Greco y L. Raffaele

2012 Volviendo a la Loma Rica de Shiquimil. Informe sobre el trabajo de campo de año 2009. Entre Pasados y Presentes 3. Estudios contemporáneos en Ciencias Antropologicas (comp. por N. Kuperszmit, T. Lagos Mármol, L. Mucciolo y M. Sacchi), pp. 910-923. Mnemosyne, Buenos Aires.

Belotti López de Medina, C. R. y M. F. Bugliani

2019 Primeros resultados zooarqueológicos del sitio tardío Loma L'Ántigo, Valle del Cajón (Catamarca) [Póster]. V Congreso Nacional de Zooarqueología Argentina, San Fernando del Valle de Catamarca. Ms.

Binford, L.

1978 Nunamiut ethnoarchaeology. Academic Press, Nueva York.

1981 Bones: Ancient Men and Modern Myths. Academic Press, Nueva York.

Borrero, L.

1990 Fuego-Patagonia Bone assemblage and the Problem of Comunal Guanaco Hunting. Hunters of the Recent Past (ed. por L. Davis y B. Reeves), pp. 373-399. One World Archaeology. Unwin Hyman, Londres.

Bugliani, M. F.

2012 Loma l'Ántigo: Consideraciones sobre la arquitectura de un poblado tardío en el valle del Cajón (Catamarca, Argentina). Comechingonia 16: 71-84.

Cantarelli, V., D. Rampa y M. Grattone

2014 Dos sitios de altura en la Sierra del Cajón. El estado actual de las investigaciones en la Localidad arqueológica de Pichanal, provincia de Catamarca. La Zaranda de Ideas 10: 9-28.

Cartajena, I.

2002 Los conjuntos arqueofaunísticos del Arcaico Temprano en la Puna de Atacama, Norte de Chile. Tesis Doctoral Inédita. Freie Universität Berlin, Impresa en microfilm, ABESY Vertriebs GMBH, Berlín.

Coll Moritan, V. y J. Nastri

2015 Organización social y asentamientos Intermedio Tardíos en el Valle de Santa María: problemas y vías de análisis. Arqueología 21: 67-87. 
Church, R. R. y R. L. Lyman

2003 Small fragments make small differences in efficiency when rendering grease from fractured artiodactyl bones by boiling. Journal of Archaeological Science 30: 10771084.

David, B.

1990 How was this bone burnt? Problem solving in taphonomy: archaeological and paleontological studies from Europe, Africa and Oceania (ed. por S. Solomon, I. Davidson y D. Watson), pp. 65-79. Tempus, Queensland.

2007 Technology on bone and antler industries: a relevant methodology for characterizing early post-glacial societies (9th-8th millennium BC). Bones as Tools: Current Methods and Interpretations in Worked Bone Studies (ed. por C. Gates St-Pierre y R. B. Walker), pp. 35-50. BAR International Series 1622, Archaeopress, Oxford.

de Guerrero, L. R.

1968 Análisis: Restos óseos de animales - SSalLap2. Ms.

Elkin, D.

1996 Arqueozoología de Quebrada Seca 3: Indicadores de subsistencia humana temprana en la Puna Meridional Argentina. Tesis Doctoral Inédita. Facultad de Filosofía y Letras, Universidad de Buenos Aires.

Escola, P. S.

2002 Caza y pastoralismo: Un reaseguro para la subsistencia. Relaciones de la Sociedad Argentina de Antropología 27: 233-245.

Gasco, A.

2013 Caza y pastoreo de camélidos en la frontera meridional del "mundo" andino. Una aproximación osteométrica. Tesis Doctoral Inédita. Facultad de Filosofía y Humanidades. Universidad Nacional de Córdoba, Córdoba.

Grayson, D. K.

1984 Quantitative Zooarchaeology: Topics in the Analysis of Archaeological Faunas. Academic Press, Orlando.

Greco, C.

2012 Integración de datos arqueológicos, radiocarbónicos y geofísicos para la construcción de una cronología de Yocavil y alrededores. Tesis Doctoral Inédita. Facultad de Filosofía y Letras, Universidad de Buenos Aires.

2018 Photogrammetric survey with UAV of strategic villages of Yocavil (Catamarca, Argentina). Political Landscapes of the Late Intermediate Period in the South-Central Andes. The Pukaras and their hinterland (ed. por A. Álvarez Larrain y C. Greco), pp. 35-60. Springer, Cham. 
Haynes, G.

1980 Evidence of Carnivore Gnawing on Pleistocene and Recent Mammalian Bones. Paleobiology 6: 341-351.

Izeta, A. D.

2004 Zooarqueología del Sur de los Valles Calchaquies: Estudio de conjuntos faunísticos del Periodo Formativo. Tesis Doctoral Inédita. Facultad de Ciencias Naturales y Museo, Universidad Nacional de La Plata.

2007a Zooarqueología del Sur de los Valles Calchaquíes (Provincias de Catamarca y Tucumán, República Argentina): Análisis de Conjuntos Faunísticos del Primer Milenio A.D. B.A.R. International Series S1612, Oxford.

2007b Zooarqueología del Formativo del valle del Cajón (Catamarca, Argentina). Pacarina 1: 471-477.

2008 Late Holocene camelid use tendencies in two different ecological zones of Northwestern Argentina. Quaternary International 180: 135-144.

Izeta, A., y L. Cortés

2006 South American camelid palaeopathologies: Examples from Loma Alta (Catamarca, Argentina). International Journal of Osteoarchaeology 16(3): 269-275.

Izaeta, A., S. Urquiza y L. Baldini

2009 La arqueofauna del período Tardío en el NOA. Una aproximación desde los conjuntos del sitio Molinos I (provincia de Salta, R. Argentina). Arqueología 15: 63-84.

Izeta, A., M. G. Srur y R. Labarca Encina

2012 Guía osteométrica de camélidos sudamericanos. Universidad Nacional de Córdoba, Córdoba.

Kaufmann, C. A.

2009 Estructura de Edad y Sexo en Lama guanicoe (Guanaco). Estudios Actualisticos y Arqueologicos en Pampa y Patagonia. Sociedad Argentina de Antropología, Buenos Aires.

Klein, R. G. y K. Cruz-Uribe

1984 The Analysis of Animal Bones from Archaeological Sites. University of Chicago Press, Chicago.

Johnson, E.

1985 Current developments in bone technology. Advances in Archaeological Method and Theory (ed. por M. B. Schiffer), pp. 157-235. Academic Press, Nueva York.

Lanzelotti, S. y R. Spano

2015 La multitemporalidad del paisaje en la Mesada del Agua Salada (Catamarca, Argentina). Arqueología 21(1): 47-71. 
Liberani, I. y J. Hernández

[1877] 1951 Excursión arqueológica en los valles de Santa María, Catamarca. Publicación 563. Instituto de Antropología. Universidad Nacional de Tucumán.

López González, F., A. Grandal-d’Anglade y J. R. Vidal Romani

2006 Deciphering bone depositional sequences in caves through the study of manganese coatings. Journal of Archaeological Science 33: 707-717.

Lumbreras, L. G.

1969 El área cotradicional meridional andina. Boletín del Museo Nacional de Historia Natural 30: 65-79.

Lyman, R. L.

1994 Vertebrate Taphonomy. Cambridge University Press, Cambridge.

Maldonado, M. G, L. V. Neder y M. M. Sampietro Vattuone

2014 Distribución espacial de los asentamientos de los períodos de Desarrollos Regionales e Inca en el tercio central de la sierra de Quilmes (valle de YocavilTucumán). Arqueología 20: 11-38.

Menegaz, A., M. Salemme y E. Ortiz Jaureguizar

1988 Una propuesta de sistematización de caracteres morfométricos de los metapodios y las falanges de Camelidae. En De procesos, contextos y otros huesos (ed. por N. Ratto y A. Haber), pp. 53-64. FFyL-ICA, Buenos Aires.

Mengoni Goñalons, G. L.

1991 Análisis de los restos óseos de camélido recuperados en la localidad de «Las Pailas» (Salta). Ms.

2013 El aprovechamiento de fauna en sociedades complejas: Aspectos metodológicos y su aplicación en diferentes contextos arqueológicos del NOA. En Al borde del imperio, paisajes sociales, materialidad y memoria en áreas periféricas del noroeste argentino (ed. por V. Williams y M. B. Cremonte), pp. 311-396. Sociedad Argentina de Antropología, Buenos Aires.

De Nigris, M. y G. Mengoni Goñalons

2005 The Guanaco as a Source of Meat and Fat in the Southern Andes. En The Zooarchaeology of the Fats, Oils, Milk and Dairying (ed. por J. Mulville y A. Outram), pp. 160-166. Oxbow Books, Oxford.

Miller, C. E., N. J. Conard, P. Goldberg y F. Berna

2010 Dumping, sweeping and trampling: experimental micromorphological analysis of anthropogenically modified combustion features. Palethnologie 2: 25-37. 
Nielsen, A. E.

2001 Evolución social en Quebrada de Humahuaca (AD 900-1536). Historia Argentina Prehispánica (ed. por E. Berberíán y A. Nielsen), pp. 171-264. Editorial Brujas, Córdoba. 2018 Agropastoral Taskscapes and Seasonal Warfare in the Southern Andes During the Regional Developments Period (Thirteenth-Fifteenth Centuries). En Political Landscapes of the Late Intermediate Period in the South-Central Andes. The Pukaras and their hinterland (ed. por A. Álvarez Larrain y C. Greco), pp. 247-268. Springer, Cham.

Olsen, S. L. y P. Shipman

1988 Surface modification on bone: trampling versus butchery. Journal of Archaeological Science 15: 535-553.

Outram A. K.

2001 A New Approach to Identifying Bone Marrow and Grease Exploitation: Why the "Indeterminate" Fragments should not be Ignored. Journal of Archaeological Science 28: $401-410$.

Páez, M. C. y G. Alé Marinangeli

2016 Huancas and rituals of fertility in the farming landscape of the northern Calchaquí Valley (Salta, Argentina). Latin American Antiquity 27(1): 115-131.

Palamarczuk, V., C. Raices Montero, M. C. García, C. Molina, M. B. Daizo, N. Petrucci, S. Lanzelotti, M. Lamamí y C. Greco

2016 El Colorado. Avances en las investigaciones arqueológicas en una localidad del sur de Yocavil, Catamarca, Argentina. Actas del XIX Congreso Nacional de Arqueología Argentina: 432-433. San Miguel de Tucumán.

Pratolongo, G.

2008 Estudio de los restos faunísticos de dos sitios tardíos en el valle de Yocavil, provincia de Catamarca: Rincón Chico 15 y Las Mojarras. Estudios arqueológicos en Yocavil (ed. por M. Tarragó y L. R. González), pp. 81-126. Asociación de Amigos del Museo Etnográfico, Buenos Aires.

Rivolta, G.

2005 Sitio Los Cardones: análisis de un poblado estratégico. Mundo de Antes 4: 67-86.

Sampietro Vattuone, M. M., J. Roldán, J. L. Peña Monné, M. G. Lefebvre y M. A. Vattuone

2016 Las prácticas agrícolas durante del Formativo y los Desarrollos Regionales en los sitios de Molle Yaco y Yasyamayo (Valle de Santa María). En Geoarqueología de los Valles Calchaquies, Ocupaciones Humanas y Reconstrucciones Paleoambientales del Holoceno (ed. por M. M. Sampietro Vattuone y J. L. Peña Monné), pp. 185-212. Laboratorio de Geoarqueología, Tucumán. 
Sarasqueta, D.

1990 Aspectos de la biología reproductiva del Nandú Petiso (Pterocnemia pennata). Comunicación Técnica RN N 1, EEA Bariloche, INTA.

Scattolin, M., L. Pereyra Domingorena, L. Cortés, F. Bugliani, C. Calo, A. Izeta y M. Lazzari

2007 Cardonal: una aldea formativa entre los territorios de valles y Puna. Cuadernos de la Facultad de Humanidades y Ciencias Sociales 32: 211-225.

Scheinsohn, V.

2010 Hearts and Bones: Bone Raw Material Exploitation in Tierra del Fuego. BAR International Series 2024, Archaeopress, Oxford.

Shipman, P.

1981a Life History of a Fossil. Harvard University Press, Cambridge.

1981b Applications of Scanning Electron Microscopy to Taphonomic Problems. Annals of the New York Academy of Sciences 276: 357-386.

Tani, M.

1995 Beyond the identification of formation processes: behavioral inference based on traces leftby cultural formation processes. Journal of Archaeological Method and Theory 2(3): 231-252.

Tarragó, $\mathrm{M}$.

2000 Chacras y pukara. Desarrollos sociales tardíos en el Noroeste. Nueva Historia Argentina. Los Pueblos Originarios y la Conquista (dir. por M. Tarragó), pp. 257-300. Sudamericana, Buenos Aires.

2011 Poblados tipo pukara en Yocavil. El plano de Rincón Chico 1, Catamarca, Argentina. Estudios Sociales del NOA/ Nueva Serie 11: 33-61.

Tarragó, M., S. Caviglia, M. Peralta Sanhuesa y J. Sosa

1988 Los grupos cerámicos del poblado de la Loma Rica de Shiquimil, Catamarca, Argentina. IX Congreso Nacional de Arqueología Argentina. Buenos Aires. Ms.

Vilá, B.

2012 Camélidos sudamericanos. Eudeba, Buenos Aires.

Williams, V.

2003 Nuevos datos sobre la prehistoria local en la Quebrada de Tolombón. Pcia. de Salta. Argentina. Anales Nueva Epoca 6: 163-209.

Williams, V., M. P. Villegas y M. C. Castellanos

2020 Pukaras en el Valle Calchaquí medio (Salta, Argentina). Anales de Arqueología y Etnología 75(1): 78-114. 
Yacobaccio, H., C. Madero, M. P. Malmierca y M. C. Reigadas

1997 Caza, domesticación y pastoreo de camélidos en la Puna argentina. Relaciones de la Sociedad Argentina de Antropología 22-23: 389-418.

Yacobaccio, H., C. Madero y M. P. Malmierca

1998 Etnoarqueología de pastores surandinos. Grupo de Zooarqueología de Camélidos, Buenos Aires. 